\title{
Avaliação microbiológica de saladas cruas servidas em restaurantes do tipo self-service do município de Volta Redonda (RJ)
}

\section{Microbiological assessment of unbleached salads served in the restaurants of the self-service type of the municipality of Volta Redonda (RJ)}

\author{
1 Aline Cristina Teixeira Mallet alinectmallet@gmail.com \\ 2 Khetlyn Souza Rocha \\ ${ }^{3}$ Cyntia Ferreira de Oliveira \\ ${ }^{3}$ Margareth Lopes Galvão Saron \\ ${ }^{3}$ Elton Bicalho de Souza
}

\author{
Centro Universitário de Volta Redonda - UniFOA, Centro Universitario de Barra Mansa - UBM. \\ Egresso do Centro Universitário Volta Redonda - UniFOA. \\ 3 Docente Centro Universitário de Volta Redonda - UniFOA
}

\section{Resumo}

As saladas cruas são alimentos que apresentam um alto risco de contaminação microbiológica, podendo iniciar na produção da matéria-prima e se estender até o armazenamento dos produtos prontos para consumo. A manipulação incorreta comprometerá a sua qualidade final, tornando-os mais propícios a causarem surtos de Doenças Transmitidas por Alimentos. Sob esse ponto de vista, o presente trabalho teve como objetivo avaliar, através de indicadores higiênico-sanitários, a qualidade das saladas cruas fornecidas pelos restaurantes do tipo self-service da cidade de Volta Redonda (RJ). Foram coletadas nove amostras em restaurantes, de forma aleatória, para analisar a presença de coliformes a $45^{\circ} \mathrm{C}$ e Staphylococcus coagulase positiva. Segundo a resolução RDC $n^{\circ} 12$ de 2001, o limite de tolerância de coliformes a $45^{\circ} \mathrm{C}$ é de $10^{2} \mathrm{NM}$ $\mathrm{P} / \mathrm{g}$ amostra. Com base nesse limite, verifica-se que três (33\%) das saladas analisadas não estavam aptas à comercialização e, consequentemente, ao consumo humano. Foi encontrada, em uma amostra, a presença de Staphylococcus, sendo este, coagulase positiva, presumindo-se a presença de Staphylococcus aureus. As saladas cruas servidas nos restaurantes pesquisados apresentaram contagem elevadas de microrganismos. Essa contaminação é um indicativo de condições higiênicas insatisfatórias, podendo causar um risco à saúde do consumidor.

\section{Palavras-chave}

saladas cruas; restaurantes; avaliação microbiológica; doenças transmitidas por alimentos.

\begin{abstract}
The raw salads are foods that present a high risk of microbiological contamination that it is possible to initiate into the production from the raw material and to stretch out up to the storage of the ready products for consumption. Inside this context, the knowledge is of extreme importance on the real conditions of handling of these foods, since diseases of food origin are considered as one of the most frequent sanitary problems in the Country. From this point of view, the present work had as I aim to value, through indicators sanitary-hygienic, the quality of the raw salads supplied by the restaurants of the type self-service of the city of Round Turn (Rio de Janeiro). Nine samples were collected in restaurants of random form to analyse the presence of coliformes to $45^{\circ} \mathrm{C}$ and Staphylococcus coagulase makes positive. According to the resolution RDC n. 12 of 2001, the tolerance limit of coliformes her 45th $C$ is of $10^{2} \mathrm{NMP} / \mathrm{g}$ sample. On basis of this limit, one checks that three (33\%) of the analysed salads was not suitable to the marketing and, consequently, to the human consumption and the presence of Staphylococcus was found in a sample, being an East, coagulase positive, the presence of Staphylococcus aureus is presumed. This contamination is indicative of unsatisfactory hygienic conditions and may pose a risk to consumer health.
\end{abstract}

\section{Keywords}

raw salads, restaurants, microbiological, transmitted disease-for-food.

\section{Como você deve citar?}

MALLET, Aline Cristina Teixeira et al. Avaliação microbiológica de saladas cruas servidas em restaurantes do tipo self-service do município de Volta Redonda (RJ). Cadernos UniFOA, Volta Redonda, n. 34, p. 89-96, ago. 2017. 
Avaliação microbiológica de saladas cruas servidas em restaurantes

do tipo self-service do município de Volta Redonda (RJ)

\section{INTRODUÇÃO}

O intuito de se fazer uma alimentação mais saudável, aliado à falta de tempo disponível para a preparação dos alimentos e/ou para o consumo, vem despertando a preferência dos consumidores por refeições mais convenientes, no que se refere à facilidade de aquisição e preparo. Assim, o brasileiro tende a procurar restaurantes do tipo self-service para determinar qual alimento será consumido (BALTAZAR et al., 2006).

As hortaliças ganham importância no cardápio, por oferecer uma alimentação balanceada, pois são fontes de micronutrientes, fibras e de outros componentes com propriedades funcionais que ajudam a melhorar o funcionamento do organismo. Ademais, as hortaliças têm baixa densidade energética, isto é, poucas calorias em relação ao volume do alimento consumido, o que favorece a manutenção saudável do peso corporal (ROLLS; ELLO-MARTIN; TOHIL, 2004, MAGNO et al., 2011).

Em especial, quando consumidos crus, legumes e verduras podem estar contaminados por microrganismos que causam danos à saúde do consumidor, sendo muito importante a adequada higienização. De acordo com Zandonadi et al., (2007) a contaminação microbiológica pode iniciar na produção da matéria-prima e se estender às etapas de transporte, recepção, armazenamento, ocorrendo também na manipulação, por condições precárias de higiene dos manipuladores, equipamentos, utensílios, ambientes e condições inadequadas de armazenamento dos produtos prontos para consumo. Por isso, as condições higiênico-sanitárias do seu preparo são indispensáveis, pois a preparação incorreta prejudicará a sua qualidade final.

A grande proliferação de microrganismos nas saladas cruas ocorre devido ao seu teor de água, que favorece o crescimento de leveduras e bactérias; $\mathrm{pH}$ ácido, favorecendo o crescimento de bolores e leveduras; a alta manipulação durante o preparo, podendo levar a contaminação por microrganismos indicadores; além de condições inadequadas de temperatura durante o armazenamento (FRANCO; LANDGRAF, 2005).

Para garantir a segurança desses alimentos, a Resolução - RDC n 12, de 02 de janeiro de 2001, da Agência Nacional de Vigilância Sanitária - ANVISA (BRASIL, 2001), estabeleceu padrões microbiológicos em relação às bactérias Salmonella spp e coliformes a $45^{\circ} \mathrm{C}$. Segundo tais padrões, hortaliças cruas não devem apresentar Salmonella spp em $25 \mathrm{~g}$ de produto e, para coliformes, a tolerância para amostra indicativa é de $10^{2} \mathrm{NMPg}^{-1}$.

Levando em consideração o envolvimento da bactéria Staphylococcus aureus em surtos de intoxicação alimentar, as amostras, foram submetidas às análises microbiológicas para a detecção desses patógenos. A tolerância para amostra indicativa teve como parâmetro para contagem em placas $10^{3} \mathrm{UFCg}^{-1}$, que é o limite máximo tolerado para outros alimentos crus, uma vez que a ANVISA (BRASIL, 2001) não menciona padrão dessas bactérias para saladas.

Para avaliar a qualidade microbiológica no estudo, foram pesquisados microrganismos indicadores, uma vez que coliformes termotolerantes (Col. Termotolerantes) indicam contaminação por material de origem fecal e, os Staphylococcus aureus (S. aureus), que no homem são encontrados na cavidade nasal. A partir desse foco, torna-se importante a análise desses microrganismos nos alimentos.

Dentro desse contexto, é de extrema importância o conhecimento sobre as reais condições de manipulação desses alimentos, já que doenças de origem alimentar são consideradas como um dos problemas sanitários mais frequentes no país. 
Dado o interesse pelo consumo alimentar de folhosos e a preocupação com a qualidade microbiológica, o presente estudo teve como objetivo avaliar a presença de bactérias patogênicas e/ou indicadoras de condições higiênico-sanitárias em saladas cruas fornecidas pelos restaurantes do tipo self-service da cidade de Volta Redonda (RJ).

\section{METODOLOGIA}

0 estudo é do tipo transversal quantitativo, realizado em 9 (nove) restaurantes de Volta Redonda - RJ, escolhidos aleatoriamente, de grande porte. Foram coletadas amostras de beterraba, cenoura, tomate e alface crus, sendo coletadas com talher comum do próprio restaurante, em horário de distribuição, transferidas para sacos plásticos esterilizados, fechados, etiquetados e transportados em caixas isotérmicas com gelo, para manutenção da temperatura de refrigeração de $2^{\circ}$ a $8^{\circ} \mathrm{C}$, até a chegada ao laboratório de Microbiologia de alimentos do Centro Universitário de Volta Redonda - UniFOA, onde foram imediatamente analisadas. Foram analisados a presença de coliformes a $45^{\circ} \mathrm{C}$ e Staphylococcus coagulase positiva.

Para a contagem de coliformes totais e termotolerantes $\left(45^{\circ} \mathrm{C}\right)$, utilizou-se a técnica do Número mais Provável (NMP), empregando séries de três tubos. 0 teste presuntivo constituiu-se pela homogeneização de $1 \mathrm{~mL}$ de cada amostra, em $9 \mathrm{~mL}$ de água peptonada $(0,1 \%)$. Em seguida, foram realizadas diluições seriadas em água peptonada a $0,1 \%$. Alíquotas de $1 \mathrm{~mL}$ das diluições apropriadas foram semeadas em Caldo Lauril Sulfato Triptose e incubadas a $35^{\circ} \mathrm{C}$ por $24-48$ horas. Após esse período, os tubos positivos, com apresentação de gás e turvação, foram transferidos para tubos contendo Caldo Verde Brilhante (Caldo VB) e incubados a $37^{\circ} \mathrm{C}$ por $24-48$ horas, constituindo-se essa etapa no teste presuntivo dos tubos positivos. Para o teste confirmativo, alíquotas de cultura dos tubos positivos em Caldo VB foram transferidas com auxílio de alça de níquel cromo para tubos contendo Caldo Escherichia coli (Caldo EC), as quais foram incubadas a $45^{\circ} \mathrm{C}$ por $24-48$ horas, constituindo o teste para a determinação do NMP de coliformes termotolerantes presentes na amostra (SILVA; JUNQUEIRA, 2007).

Os resultados foram analisados de acordo com as diluições e a quantidade de amostras positivas do teste confirmativo, orientando-se pelo uso da tabela de NMP da Bacteriological Analytical Handbook.

A metodologia instituída para a pesquisa de Staphylococcus coagulase positiva foi a de Contagem Direta em Placas. Partindo das diluições $10^{-1}, 10^{-2}$ e $10^{-3}$, com o auxílio de uma pipeta esterilizada, foi transferido 0,1 mL de cada diluição para placas de Petri contendo Ágar Baird-Parker (BP) e depois espalhou-se o inóculo por toda a superfície do Ágar BP, utilizando-se a técnica de semeadura em superfície ou Spread Plate. As placas foram incubadas, invertidas, em estufa a $35^{\circ} \mathrm{C}$, por 48 horas. Posteriormente, foram selecionadas, para contagem, as placas que continham entre 20 e 200 colônias típicas. As colônias típicas (negras, brilhantes, com anel opaco, rodeado por um halo claro transparente, destacando-se sobre a opacidade do meio) foram contadas para cálculo do número de unidades formadoras de colônias (UFC) por grama do alimento. Três colônias típicas isoladas de cada placa foram repicadas para tubos contendo Caldo Infusão Cérebro-Coração (Caldo BHI). Emulsionou-se a massa de células com o caldo e foi transferida uma alçada para um tubo com Ágar-Tripticase de Soja inclinado. Ambos os meios foram incubados a $35^{\circ} \mathrm{C}$ durante 24 horas. A partir do subcultivo crescido no Caldo $\mathrm{BHI}$ foi realizada a prova bioquímica de Coagulase (SILVA; JUNQUEIRA, 2007).

\section{RESULTADOS E DISCUSSÃO}

Na Tabela 1, estão expostos os resultados da quantificação de coliformes totais e termotolerantes. 
Avaliação microbiológica de saladas cruas servidas em restaurantes do tipo self-service do município de Volta Redonda (RJ)

Tabela 1 - Análises de coliformes totais e termotolerantes das amostras

\begin{tabular}{|l|l|l|}
\hline Amostra & Col.totais $\mathrm{NMPg}-1$ & Col. Termotolerantes $\left(\mathbf{4 5}^{\circ} \mathrm{C}\right) \mathrm{NMPg}-1$ \\
\hline A & $2,4 \times 10^{3}$ & $2,3 \times 10^{2}$ \\
\hline B & $1,1 \times 10^{4}$ & $<3,6$ \\
\hline C & $2,4 \times 10^{3}$ & $9,2 \times 10$ \\
\hline D & $1,1 \times 10^{4}$ & $1,1 \times 10^{4}$ \\
\hline E & $1,1 \times 10^{2}$ & $<3,6$ \\
\hline F & $3,5 \times 10^{2}$ & $<3,6$ \\
\hline G & $2,1 \times 10^{2}$ & $2,1 \times 10^{2}$ \\
\hline H & $1,5 \times 10^{2}$ & $<3,6$ \\
\hline I & $2,0 \times 10^{2}$ & $<3,6$ \\
\hline
\end{tabular}

Fonte: dos autores, 2017.

Considerando os resultados mencionados para coliformes totais, observa-se que os noves locais pesquisados apresentaram contagem elevada para tais bactérias.

Os resultados das análises evidenciam condições higiênicas insatisfatórias, podendo-se considerar que os nove estabelecimentos praticam de forma incorreta a higienização das hortaliças, constituindo-se um fator de risco ao consumidor.

O benefício da análise microbiológica feita nas saladas cruas fornecidas nos restaurantes self-service é garantir a qualidade e a segurança dos consumidores que consomem esse tipo de produto.

As contagens totais de bactérias em hortaliças são utilizadas como parâmetros da carga microbiana presente, não indicando se a população tem efeito benéfico ou prejudicial. Contudo, servem como alerta das condições de higiene durante a manipulação e armazenamento, como também dos potenciais riscos oferecidos à saúde do consumidor (BRASIL, 2001).

Embora não existam informações na legislação quanto aos limites de contagens para coliformes totais, tais análises foram realizadas considerando-se que os resultados positivos indicam as más condições higiênicas do local, do produto e o risco da presença de patógenos fecais.

Coliformes termotolerantes são bactérias na forma de bastonetes Gram-negativos, não esporogênicos, aeróbios ou anaeróbios facultativos, capazes de fermentar a lactose com produção de gás, em 24 horas a $44,5^{\circ}-45,5^{\circ} \mathrm{C}$, sendo membro das bactérias coliformes fecais (SILVA; JUNQUEIRA; SILVEIRA, 2001). Os microrganismos causadores de doenças alimentares podem ser transmitidos pelos dedos de manipuladores de alimentos com hábitos de higiene insatisfatórios, por insetos voadores ou rasteiros e também pela água (JAY, 2005).

Segundo a Resolução RDC n 12 de 2001, o limite de tolerância de coliformes a $45^{\circ} \mathrm{C}$ é de $10^{2}$ $\mathrm{NMPg}^{-1}$ amostra (BRASIL, 2001). Com base nesse limite, verifica-se que três (33\%) das amostras de saladas analisadas encontravam-se fora dos limites preconizados, não estando aptas à comercialização e, consequentemente, ao consumo humano. 
Os valores encontrados assemelham-se aos apresentados por Araujo (2014), que verificou em $30 \%$ das amostras um valor acima do permitido estabelecido pela mesma resolução.

Pereira e Hoffmann (2011) avaliaram a qualidade microbiológica de vegetais minimamente processados comercializados na cidade de São José do Rio Preto - SP e encontraram $80 \%$ das amostras analisadas positivas para coliformes termotolerantes e acima dos níveis permitidos, indicando condições higiênico-sanitárias inadequadas de bancadas, utensílios e manipuladores.

O estudo feito por Azerêdo, Conceição e Stamford (2004) encontrou 15,3\% das amostras de alimentos frios, incluindo saladas, positivas para coliformes a $45^{\circ} \mathrm{C}$ e os valores variaram de 4 a $>1100 \mathrm{NMP} / \mathrm{g}$. De forma similar, no estudo de Ribeiro e Pietro (2006), verificou-se presença de coliformes fecais em alface minimamente processada, com resultados acima do recomendado, indicando condições higiênicas não satisfatórias.

A detecção de Staphylococcus coagulase positiva, também não prevista na legislação para esse tipo de produto, foi realizada através de análises microbiológicas de contagem total em placas e posterior teste de coagulase. No que diz respeito à quantidade desses microrganismos, pode-se dizer que a tolerância para alimentos, de modo geral, é de $10^{3} \mathrm{UFCg}^{-1}$, conforme a ANVISA (BRASIL, 2001). Das amostras analisadas, foi encontrada em apenas uma $11 \%$ contagens de Staphylococcus superiores ao estabelecido pela legislação, sendo coagulase positiva, presumindo-se a presença de $S$. aureus na amostra.

De acordo com Martins (2002), os estafilococos são cocos Gram-positivos, catalase positivos, que tendem a formar agrupamentos semelhantes a cachos de uva. 0 gênero é composto por, aproximadamente, 27 espécies, algumas mais frequentemente associadas a infecções oportunistas, tanto em seres humanos quanto em animais. Tradicionalmente, são divididos em duas categorias: coagulase postivos e negativos. Entre os que são considerados coagulase positivos, $S$. aureus representa a espécie com maior probabilidade de envolvimento em infecções humanas.

Alimentos ou superfície contendo a presença de Staphylococcus spp pode ser interpretada como indicador de contaminação pelos manipuladores e indicativo de ausência de controle higiênico-sanitário nos processos de produção de alimentos e na qualidade de sanitização das superfícies destinadas ao contato com os alimentos (GUIMARÃES; ANDRADE, 2008).

Segundo Silva Junior (2001), para que as mãos dos manipuladores sejam consideradas limpas, essas devem ser higienizadas a cada 1 hora, o que não ocorre nos estabelecimentos. A literatura brasileira vem demonstrando que o perfil higiênico-sanitário dos manipuladores de alimentos tem se mostrado, muitas vezes, inaceitável, quanto à contaminação microbiana encontrada em diversos sítios anatômicos.

Segundo Silveira et al. (2003), a contratação de pessoas despreparadas e desqualificadas para serviços de manipulação de alimentos pode prejudicar a qualidade higiênico sanitária dos alimentos.

A implantação de um Manual de Boas Práticas em estabelecimento produtor de alimentos é fundamental para a produção e comercialização de alimentos saudáveis e que não apresentem riscos de contaminação à saúde dos consumidores.

Implantando o programa de Boas Práticas de Fabricação, estabelecido pela Portaria $n^{\circ} 326$, de 30 de julho de 1997, da ANVISA, que é um regulamento técnico sobre as condições higiênico-sanitárias e de Boas Práticas de Fabricação para Estabelecimentos Produtores de Alimentos, previne-se os riscos 
microbiológicos, atingindo um alto padrão de qualidade dos alimentos. Elas são compostas por um conjunto de princípios e regras para o correto manuseio de alimentos, que abrangem desde a recepção das matérias-primas até o produto final. 0 seu principal objetivo é garantir a integridade do alimento e a saúde do consumidor (NASCIMENTO; BARBOSA, 2007).

O Manual de Boas Práticas de Produção contém processos que servem para garantir a qualidade e a identidade dos alimentos e dos serviços, além da saúde do consumidor (ABREU; SPINELLI; PINTO, 2003).

Segundo Rego (2004), o Manual de Boas Práticas deve conter uma descrição real dos procedimentos técnicos para cada estabelecimento, em especial, entre os quais: controle de saúde dos funcionários, controle da água para consumo, controle integrado de pragas, regras para visitantes, controle das matérias-primas, adequação estrutural do estabelecimento, higiene pessoal, ambiental e de alimentos, manipulação e processamento dos alimentos nas etapas básicas de preparação (recebimento, armazenamento, pré-preparo, coç̧ão, refrigeração, congelamento, descongelamento, reaquecimento, porcionamento, distribuição e transporte).

\section{CONCLUSÃO}

Com o desenvolvimento deste estudo, observou-se que os restaurantes estão fornecendo saladas cruas com contagens elevadas de microrganismos, podendo comprometer a saúde do cliente. Esses resultados podem ser indicativos de contaminação pelos manipuladores e indicativo de ausência de controle higiênico-sanitário dos processos de produção das saladas, assim como o tempo prolongado de exposição durante a distribuição no decorrer do horário do almoço.

Concluímos que os restaurantes pesquisados na cidade de Volta Redonda (RJ) precisam melhorar as condições higiênicas sanitárias das saladas cruas que comercializam, uma vez que surtos causados por microrganismos podem causar doenças graves, sobretudo em crianças, idosos e imunodeprimidos.

\section{AGRADECIMENTOS}

Os autores da pesquisa agradecem à técnica de Laboratório de Microbiologia de Alimentos do UniFOA, Maiara da Silva, pela contribuição na realização da pesquisa. 


\section{REFERÊNCIAS}

ABREU, E.S.; SPINELLI, M.G.N.; ZANARDI, A. M. P.; Gestão de unidade de alimentação e nutrição: um modo de fazer. São Paulo: Metha, 2003.

ARAÚJO, J.F.D.P.; Análise Microbiológica de Alimentos Folhosos Preparados em Restaurantes e em Residências. Faculdade de Ciências da Educação e Saúde, Brasília, 2014.

AZERÊDO, G.A.; CONCEIÇÃO, M.L.; STAMFORD, T.L.M.; Qualidade higiênico-sanitária das refeições em um restaurante universitário. Revista Higiene Alimentar. V.18, n.125 p.74-8, 2004.

BALTAZAR, C.; SHIMOZAKO, H.J.; AMAKU, M.; PINHEIRO, S.R.; PERONDI, A.M.T. Avaliação higiênico sanitária de estabelecimentos da rede fast food no município de São Paulo. Revista Higiene Alimentar. v.20, n.142, p.46- 51, 2006.

BRASIL. Ministério da Saúde. Agência Nacional de Vigilância Sanitária. Resolução RDC n. 12 de 02 de janeiro de 2001. Dispõe sobre o regulamento técnico sobre padrões microbiológicos para alimentos. Diário Oficial da República Federativa do Brasil, Brasília, DF, 2001.

FRANCO, B.D.G.M; LANDGRAF, M. Microbiologia dos alimentos. São Paulo: Atheneu, 2005.

GUIMARÃES, K. A. S.; ANDRADE, A. S. Contaminação de produtos lácteos por Staphylococcus aureus: revisão bibliográfica. Revista Higiene Alimentar, São Paulo, v.22, n.163, p.56-62, 2008.

JAY, J.M.; Microbiologia dos Alimentos. Porto Alegre: Artmed, 2005.

MAGNO, S. et al. Análise microbiológica de saladas servidas em restaurantes da cidade de Pombal PB. Caderno Verde de Agroecologia e Desenvolvimento Sustentável, v.1, n.1 2011.

MARTINS, L. T. Staphylococcus. In: TRABULSI, L. R. et al. Microbiologia. 3. ed. São Paulo: Editora Atheneu, 2002. p. 149-156.

NASCIMENTO, G.A.; BARBOSA, J.S. BPF - Boas Práticas de Fabricação: uma revisão. Revista Higiene Alimentar, São Paulo, v.21, n.148, p.24-30, 2007.

PEREIRA, A.P.M.; HOFFMANN, F.L. Qualidade microbiológica de vegetais minimamente processados comercializados na cidade de São José do Rio Preto, SP. Revista Higiene Alimentar. v. 25, n. 196/197, p. 60- 63, 2011.

REGO, J. C. Qualidade e segurança de alimentos em unidade de alimentação e nutrição. Total de folhas 124. Tese - Universidade Federal de Pernambuco. Recife, 2004.

RIBEIRO, M.; PIETRO, R.C.L.R.; Avaliação microbiológica de vegetais folhosos in natura minimamente processados. Revista Higiene Alimentar. v.20, n. 66, 2006.

ROLLS, B.J.; ELLO-MARTIN, J.A.; TOHILL, B.C.; What can intervention studies tell us about the relationship between fruit and vegetable consumption and weight management. NutrReviews, v.62, $n^{\circ} 1, \mathrm{p} 1-17,2004$.

SILVA JUNIOR, E. S. Manual de controle higiênico- sanitário em alimentos. 4. ed. São Paulo: Varela, 2001. 
SILVA, N.; JUNQUEIRA, V.C.A.; SILVEIRA, N.F.A.; TANIWAKI, M.H.; SANTOS, R.F.S.; GOMES, R.A.R. Manual de métodos de análise microbiológica de alimentos. 3. ed. São Paulo: Livraria Varela. 2007.

SILVEIRA, I. A.; OLIVEIRA, E. C. M.; POSSATO, I. P.; GUIMARÃES, L. C.; SANTOS, S.; COELHO, A. E. A.; SANTANTA, B. F. Monitoramento microbiológico das mãos de funcionários de uma cantina universitária na cidade de Lavras - MG. Revista Higiene Alimentar, v.17, n. 104/105, 2003.

ZANDONADI, R.P. et al. Atitudes de risco do consumidor em restaurantes de auto serviço. Revista de Nutrição. Campinas, v.20, n.1, p.19-26, 2007. 